\title{
CONGENITAL DEFECTS FOLLOWING RUBELLA REPORTS OF TWO CASES, ONE OF WHICH SHOWS A HITHERTO UNDESCRIBED LESION
}

\author{
BY \\ IAN MACKENZIE, A. P. PRIOR, AND A. HOLZEL \\ From the Department of Pathology, Warwickshire County Council, and the \\ Department of Child Health, University of Manchester
}

(RECEIVED FOR PUBLICATION, JUNE 29, 1948)

The association of maternal rubella in the third month of pregnancy with ocular defects in the infant was first noticed in New South Wales by Gregg (1941). Subsequently (1946) the matter was investigated by Swan and his collaborators in South Australia. Further investigations have been made in the United States and in this country. By now there have also been reports of maternal rubella preceding the following defects in the infant: congenital abnormalities of the heart, abnormal size of the head, deafness, feeding difficulties, subnormal weight.

Apart from records by Swan (1944) very few post-mortem observations have been made. His "Final Report" (1946) mentions " heart disease" in a number of the cases, but there are no further post-mortem records. We have been unable to trace any such records in this country. The already voluminous literature on the subject deals in the main with case reports, probabilities, and theories of mechanism.

The purpose of the present paper is to record two further instances in which post-mortem examinations were made and to discuss relevant findings.

\section{Case Reports}

Case 1.-An infant was born to a primipara of 26 years. It was known that the mother had had rubella when ten weeks pregnant. The delivery was normal, but the child lived for only fifteen minutes.

Post-mortem findings. - Full-term female child weighing $6 \mathrm{lb}$. There were no external abnormalities. The body was radiographed, but no bony abnormalities found. The eyes were bisected and found normal. Cranium and brain were also normal.

The thorax and abdomen were anatomically grossly abnormal (Plate II). The small bowel and the left lobe of the liver (1) were seen to be in the thoracic cavity. The heart (2) and lungs were deviated to the right, and both lungs were much compressed. $\mathbf{A}$ thin edge of both lobes of the left lung ran diagonally across the thorax (3) from the apex of the cavity to the lower right-hand corner, where it met the displaced heart and pericardium. A large thymus gland (4) covered the upper portion of the pericardium and filled the whole of the superior mediastinum.

The right muscular portion of the diaphragm was well formed $(5,16)$. The posterior muscular portion of the left half of the diaphragm was present (17), but there was no anterior two-thirds of the left half of the diaphragm (6). Through the gap thus made had herniated the left lobe of the liver, the stomach and nearly all the small intestines, the spleen, the pancreas, and in an extraordinary fashion the bulk of the colon.

The caecum and appendix were to the left of the mid-line in the epigastric region (7). The ascending colon (8) traversed the left side of the liver and stomach to reach the top of the left thoracic cavity. It descended (9) antero-superiorly to the spleen (21), which itself lay on the left diaphragm, to come into more normal lateral relationship with the left kidney (13).

The pelvic colon (10) was unnaturally mobile and ran from the left iliac fossa upwards and then across in a wide sweep to the right iliac fossa, where it entered the pelvis minor on the right side. In its sweep it embraced the left ovary and fallopian tube which lay on its mesentery to the right side of the mid-line. The uterus (11) was rotated through 30 degrees, so as to face to the left.

The heart (2) was of normal size and shape, although it lay in the right thoracic cavity.

There was a large patent inter-auricular septum, but no interventricular communication. The pulmonary artery was of average size, both in length and diameter. The ductus arteriosus was more prominent and of wider lumen than the aorta. It was $2 \mathrm{~cm}$. in length from the origin of the left pulmonary artery to its junction with the aorta beyond the left subclavian artery. It formed a complete right angle with the descending aorta, and ran almost parallel to the ascending aorta in the manner shown (see diagram).

In its descending and abdominal portions the aorta appeared to be normal in length, lumen, and anatomi- 

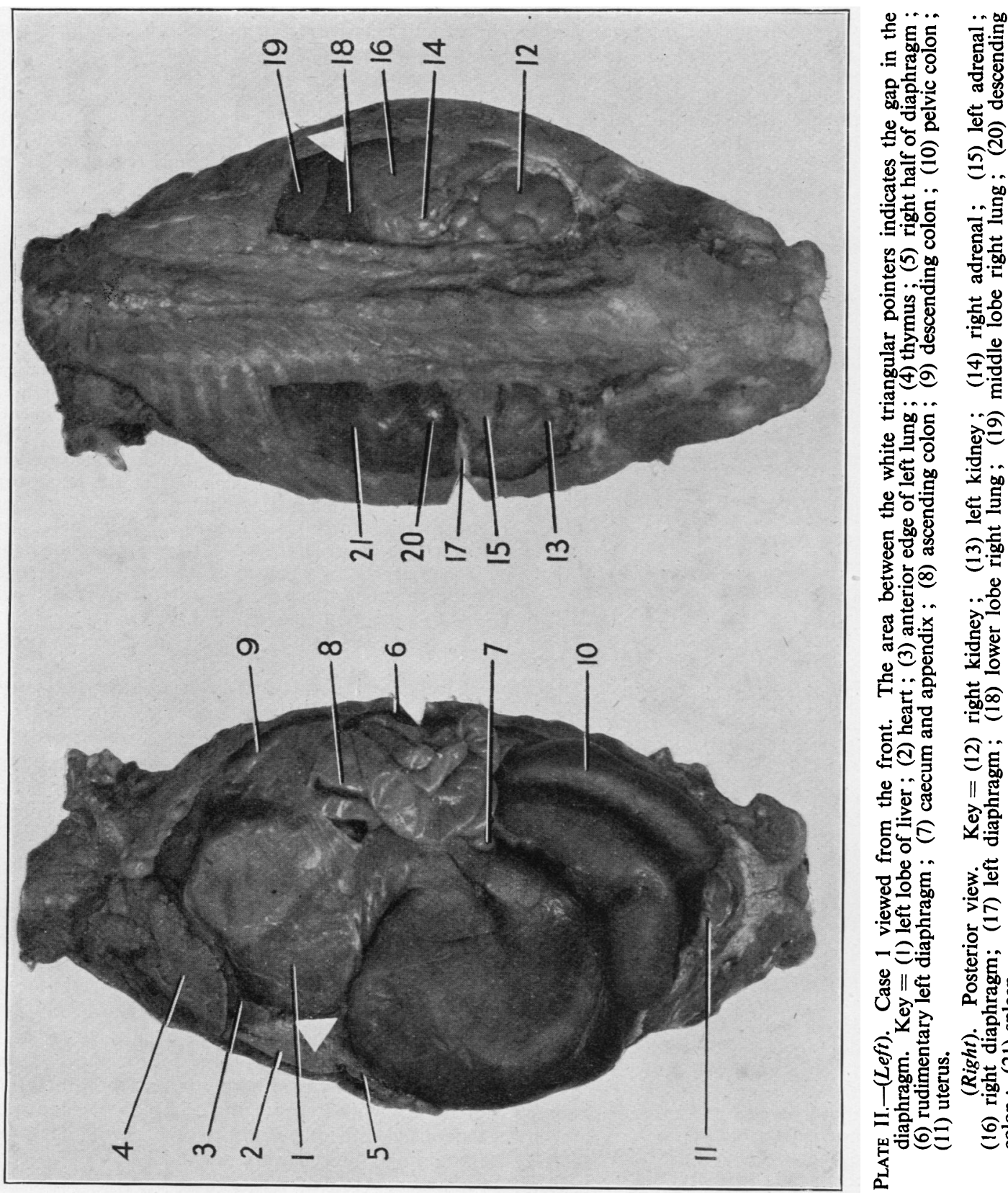

छํํ음 壳要 要前 㝳氙

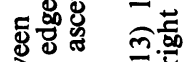
可 잉

Ð

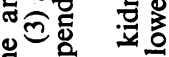
붕 壱命

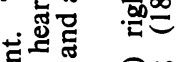

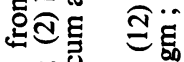

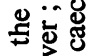
E气

$x:=$

휴욯

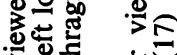
可专 - 气罵

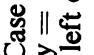

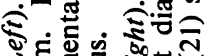

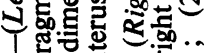
봉흐

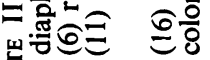
文 
cal position. Although the trachea was anatomically displaced to the right, it was normal in size and shape.

The oesophagus maintained normal relationship with the aorta until its emergence at the diaphragm. There was no diaphragm to the left and anteriorly, although there was a thin muscular slip to the left posteriorly, and a fully formed diaphragm to the right.

The stomach lay along the left border of the dorsal vertebrae and it was of normal size and shape. No abnormality of pylorus or duodenum was observed.

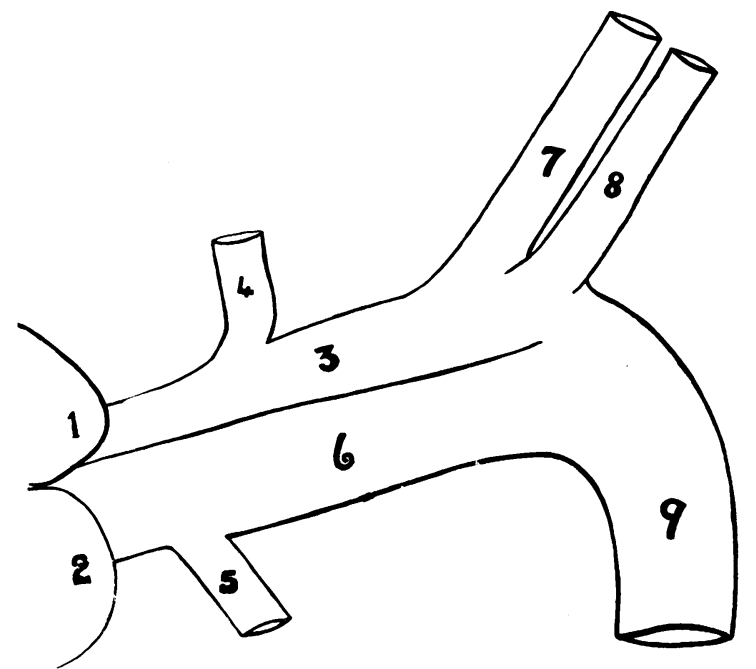

Relations between the aorta, pulmonary artery, and ductus arteriosus in Case 1. Key = (1) right auricle; (2) left auricle; (3) ascending aorta ; (4) innominate artery; (5) left pulmonary artery ; (6) ductus arteriosus; (7) right carotid artery ; (8) subclavian artery; (9) descending aorta.

The kidneys (12 and 13) were normal anatomically and histologically. So were the ureters and bladder. The adrenal glands (14 and 15) were normal in size, shape, and position. The pancreas was displaced upwards into the left thoracic cavity. The spleen (21) lay on the thin slip of left diaphragm within the chest wall.

Case 2. - A male baby of three days was admitted with his mother to hospital because of marked oedema of the lower half of the body, jaundice, vomiting, and loose stools. This infant, the second child, was born at home. Delivery had been normal, and the weight at birth was $6 \mathrm{lb}$. $9 \mathrm{oz}$.

Two events had interrupted the otherwise normal course of pregnancy. Towards the end of the third month of the pregnancy the mother had contracted rubella. The infection was mild and did not appreciably affect her general condition. At four months she was threatened by abortion. After a few days' rest in bed the danger passed, and the further course of the pregnancy remained uneventful.

The first child, aged 15 months, was well. The parental history did not reveal anything relevant.
Clinical findings.-The infant was normal, well developed, slightly jaundiced, with extensive oedema of feet, legs, scrotum, and genital area, sacral region, and lower abdominal wall. Heart, lungs, abdomen, urine, and blood were all normal. Bilateral cataracts were noticed a few days after admission. Apart from a large anterior fontanelle the skull was normal.

In the course of the following week oedema subsided and the jaundice cleared completely; the infant took the breast well and started to gain weight. On the tenth day after admission mother and baby left hospital.

Fourteen days later the infant, now artificially fed, developed fulminant bronchopneumonia and parenteral gastro-enteritis, and was readmitted in a moribund condition. He died within thirty-six hours.

Post-mortem findings. - The body appeared normally formed but was small. There was slight dehydration. There was bilateral congenital cataract. Out of deference to the parents the eyes were not removed. The cause of death was bilateral pneumonia, more advanced in the right lung. The heart was typically "sabot" shaped. There was dilatation of the right chambers. The ductus arteriosus was widely patent, its lumen not much less than that of the pulmonary artery, although the wall was thinner. Its endothelium was smooth, unwrinkled, and directly continuous with that of the larger arteries. Microscopic examination did not show any evidence of obliterative endarteritis in the patent ductus arteriosus. No abnormality was found in the glomeruli of the kidneys.

\section{Discussion}

The association of rubella in the first three months of pregnancy with congenital defects in the foetus has been noted by Clayton-Jones (1947), Hughes (1945), and Hope-Simpson (1944) amongst others in this country. Most investigations have been made by tracing histories from children showing congenital defects to a maternal infection (Swann, 1944 ; Clayton-Jones, 1947 ; Conte and others, 1945 ; Erickson, 1944).

A different line of investigation was followed by Fox and Bortin (1946). They reviewed the notifications of rubella in a certain community over a period of three years. The total number of cases in all classes of people was more than 22,000 . Of 152 married women notified, eleven were pregnant. Nine of these were in the first four months of their term. In these cases there was one twin birth, one blue baby with hydrocephalus which receded spontaneously, and one stillborn hydrocephalic. The remaining children were normal.

Parsons (1946a) states that causal relationship between maternal rubella and congenital defects has not been definitely proved, and in a further paper (1946b) he discusses some of the difficulties of the theory. Swan (1944) describes patency of the ductus arteriosus in his series of babies coming 
to necropsy. Gregg is quoted (Parsons, 1946b) as finding forty-four cases of congenital heart disease out of seventy-eight affected infants.

Other abnormalities described have been mental retardation, microcephaly, mongolism, hypospadias, talipes equino-varus, and synostosis of radius and ulna or tibia and fibula.

Congenital diaphragmatic hernia has not hitherto been described in the literature as one of the developmental defects occurring in association with maternal rubella.

The diaphragmatic hernia in Case 1 differs from the common form, in which all diaphragmatic segments are present but a patency exists between the pleural and peritoneal cavities. This pleuroperitoneal hiatus, or foramen of Bachdalek, may vary in size, but it is surrounded by diaphragmatic elements. Abassy has quoted Dickson as saying that diaphragmatic hernia is seen in one case out of each hundred routine gastric radiographs.

In this case there was a total absence of the anterior two-thirds of the left half of the diaphragm. There was, however, a small muscular slip to represent the posterior third of the diaphragm.

Developmentally the diaphragm arises in four main parts: a ventral, a dorsal, and a right and a left lateral. The ventral part is formed from a septum transversum which is gradually differentiated into a caudal, an intermediate, and a cephalic part. It is from the intermediate portion that the ventral part of the diaphragm is formed. The dorsal portion of the diaphragm arises from the mesoderm of the dorsal mesentery of the foregut. The two lateral portions grow towards the median plane until they fuse with the dorsal portion.

The present appearance of the diaphragm would suggest that there had been a failure of growth of the left lateral portion and of the left half of the ventral portion. It resulted in a very rudimentary left half of the diaphragm, and this gross diaphragmatic hernia.

The time of formation of the diaphragm from its various elements is from the eighth week onwards, after the pericardial cavity has already been shaped. The inter-atrial and interventricular septa begin to develop between the fourth and sixth weeks. The former is the result of the coalescence of the primary and secondary septa. Their fusion is partial and leavés the foramen ovale. The valve of the foramen is formed in the fourth month. The interventricular septum arises in the lower part of the primitive ventricle, and grows upwards to meet the endocardial cushions and the septum developing in the bulbus arteriosus. The lower part is complete about the eighth week, and the septum of the bulbus arteriosus a few days earlier.

In Case 1 the mother was stated to have suffered from rubella when ten weeks pregnant. The time of formation of the diaphragm is about the eighth week. The possibility that the maternal disease and the time of formation of the affected part coincided is not to be lightly dismissed.

In Case 2 the mother suffered from rubella at about the third month. The ductus arteriosus forms about the sixth week; the valve of the intraatrial septum about the sixteenth week ; the interatrial septum about the eighth week. Thus the infection would have had ample opportunity to interfere with the development of the cardiac septa. - Parsons (1946b) has canvassed the possibility of strain differences, as well as emphasizing the difficulties of diagnosis. This is a point which most authors in this country stress. Some support for the theory is given by Conte and others (1945), who found that the incidence of rubella in the appropriate months of pregnancy in mothers of children with congenital abnormalities was ten times the expected rate for women of the childbearing age of the population at large.

Swan and others (1946) do not deal only with rubella as an antecedent of congenital defect. They list cases in which influenza, scarlet fever, herpes zoster, varicella, and mumps, together with one of "pustular rash," were antecedents.

\section{Summary}

Post-mortem records of two infants with congenital malformations following maternal rubella are described. Case 1 presented an unusual form of congenital diaphragmatic hernia and a widely patent ductus arteriosus. Case 2 had bilateral congenital cataract and a wide patency of the ductus arteriosus.

We wish to thank Mr. G. G. Alderson, under whose care Case 1 was born and who has encouraged publication of the case; Dr. J. Wearing for taking $x$-ray photographs ; and Mr. T. L. Skuse and Mr. G. Wright for technical assistance.

\section{REFERENCES}

Abassy, A. S. A. (1945). Arch. Pediat., 62, 285.

Clayton-Jones, E. (1947). Lancet, 1, 56.

Conte, W. R., McCammon, C. S., and Christie, A. (1945). Amer. J.

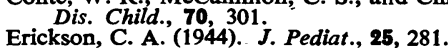

Erickson, C. A. (1944). J. Pediat. 25, 281.
Fox, M. J., and Bortin, M. M. (1946). J. Amer. med. Ass., 130, 568 , Gregg, H.' McA. (1941). Trans. Ophthalmological Soc. Aust. Brit. Med. Ass., 111, 35.

Hope-Simpson, R. E. (1944). Lancet, 1, 483.

Hughes, I. (1945). Proc. R. Soc. Med., 39, 17

Parsons, L. G. (1946a). J. Obstet. Gynaec. Brit. Emp.; 53, 1.

Parsons, L. G. (1946b). Brit. med. Bull., 4, 193.

Parsons, . (1944). J. Path. Bact., 56, 289.

Swan, C., Tostevin, A. L., and Barham Black, G. H. (1946). Med. J. Aust., 11, 889 . 